\section{Ring in the new}

\author{
Andrew Bush, ${ }^{1}$ lan Pavord ${ }^{2}$
}

Two vast collective family sighs of relief from Oxford and London were heard this month as news of the appointment of the

${ }^{1}$ National Heart and Lung Institute, Imperial College, London, UK; ${ }^{2}$ Nuffield Department of Medicine, University of Oxford, Oxford, USA

Correspondence to Professor Andrew Bush, National Heart and Lung Institute, Imperial College, London, UK; a.bush@imperial.ac.uk new editorial team for Thorax was announced (although one wife was heard to mutter "I've got him for life, it doesn't mean I want him for lunch"). Congratulations to the new NottinghamLondon axis of Nick Hopkinson, Gisli Jenkins and Alan Smyth who will take over later on this year. We are very proud that we have caused so much chaos that it will take three people to pick up the pieces. If the new team is half as well supported as we have been, they will be very well looked after indeed, and all can be confident that they will take the Journal to new heights.

Competing interests None.

Provenance and peer review Commissioned; internally peer reviewed.

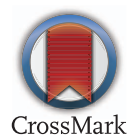

To cite Bush A, Pavord I. Thorax 2015;70:403.

Thorax 2015;70:403.

doi:10.1136/thoraxjnl-2015-207103 


\section{Correction}

Bush A, Pavord I. Ring in the new. Thorax 2015;70:403.

The editors apologise for getting the name of one of their successors wrong in last months' editorial Ring in the new. Nick Hopkinson should have read Nicholas Hart. We could cite the confusingly large numbers of Nick H's in respiratory medicine but the real reason is advancing editorial dementia. We apologise unreservedly.

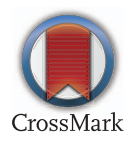

Thorax 2015;70:606. doi:10.1136/thoraxjn-2015-207103corr1 